\section{Green synthesis of Silver nanoparticles through Calotropis gigantea leaf extracts and evaluation of antibacterial activity against Vibrio alginolyticus}

\author{
Baskaralingam Vaseeharan, ${ }^{1}$ \\ Clara Gunapoorani Sargunar, ${ }^{2}$ \\ Yong Chin Lin, ${ }^{3}$ Jiann Chu Chen ${ }^{3}$
}

'Dept. Animal Health and Management, Alagappa University, Alagappa Nagar, Tamil Nadu, India; 2PG \& Research Dept. Zoology, Government Arts College (Autonomous), Tamil Nadu, India; ${ }^{3}$ Dept. Aquaculture, College of Life Sciences, National Taiwan Ocean University, Taiwan, ROC

\begin{abstract}
Green synthesized silver nanoparticles by Calotropis gigantea leaf extract were used to study the inhibitory activity against pathogenic Vibrio alginolyticus, isolated from wild Artemia franciscana cysts. Silver nanoparticle synthesis was observed using UV-visible spectroscopy and the morphological characteristics were analyzed by atomic force microscope (AFM). In the present study, increasing concentrations of silver nanoparticles synthesized on LB agar plates effectively reduced the number of colonies of $V$. alginolyticus. A decrease in colonies (CFUs) was observed at $5 \mu \mathrm{g} / \mathrm{mL}$ of silver nanoparticle concentration and the complete inhibition of $V$. alginolyticus was observed at $20 \mu \mathrm{g} / \mathrm{mL}$ of silver nanoparticle concentration on LB agar plates. In vivo controlling efficiency of silver nanoparticles was tested in an $A$. franciscana hatching system. Effective control of $V$. alginolyticus in brine shrimp $A$. franciscana hatching units was achieved by experimental infection and treatment with silver nanoparticles. Experimental infection studies showed that $V$. alginolyticus infected Artemia nauplii treated with silver nanoparticles $(10 \mu \mathrm{g} / \mathrm{mL})$ had greater survival ( $>40 \%$ ) than silver nanoparticles not treated with nauplii. Based on the findings of this study, it is recommended that low concentrations of green synthesized silver nanoparticles should be further investigated for other potential experimental models to control potential medical pathogens.
\end{abstract}

\section{Introduction}

The emergence of nanoscience and nanotechnology presents opportunities for explor- ing the bactericidal effect of metal nanoparticles. The bactericidal effect of metal nanoparticles has been attributed to their small size and high surface to volume ratio, which allows them to interact closely with microbial membranes, and is not merely due to the release of metal ions in solution. Nanophasic and nanostructure materials are attracting a great deal of attention because of their potential for achieving specific processes and selectivity, especially in biological and pharmaceutical applications. ${ }^{1}$ Technological development and applications are out-pacing research on health and environmental risks posed by nanoparticles. Like genetically modified organisms, the future of nanotechnology will depend on public acceptance of the risks versus benefits. However, the antimicrobial effects of silver nanoparticles (AgNps) have not been investigated in aquacultural practices. It is very important to note that opportunistic bacteria are one of the causative agents of disease in aquaculture, and effective, eco-friendly control methods are needed to avoid their outbreak.

Mass mortality due to infections by endemic microbes in the aquaculture industry causes severe economic loss. ${ }^{2}$ In recent decades, the use of chemotherapeutic agents and antibiotics to control microbial disease outbreaks in aquaculture has increased dramatically, and this has given rise to antibiotic resistance to pathogenic bacteria. ${ }^{3}$ Vibrio species naturally occur in culture systems and are resistant to various drugs, making these species difficult to control when outbreaks occur, as they adapt quickly to antibiotics. In this study, we have investigated the in vivo efficiency of control of AgNps against simple experimental system, i.e. Artemia hatching system. In aquaculture practice, live feeds, especially Artemia cysts, serve as the major carrier of Vibrio species in both larviculture and grow-out stages. ${ }^{4}$ During the hatching process, these Artemia nauplii are heavily contaminated, mainly with $V$. alginolyticus ${ }^{5}$ an omnipresent organism in the marine environment. It is an opportunistic pathogen of vertebrates and invertebrates $^{6}$ causing septicemia, exophthalmia, corneal opaqueness, ascites, lethargy, melanosis and ulcers in finfish. ${ }^{7} \mathrm{~V}$. alginolyticcus has been reported to cause diseases in the shrimp Penaeus monodon and necrosis in Macrobrachium rosenbergii larvae. ${ }^{8-10}$ It has also been associated with diseases in sea bream (Sparus aurata L.), grouper (Epinephelus malabaricus), sea mullet (Mugil cephalus) and red sea bream (Pagellus bogaraveo). ${ }^{5}$

Recent studies using metallic nanoparticles have demonstrated a broad range of antimicrobial activity against several gram positive, pathogenic bacteria such as Staphylococcus epidermis, S. aureus, Micrococcus luteus, ${ }^{11-13}$ gram negative pathogenic bacteria such as Klebsiella pneumoniae, Salmonella typhi, V. cholera, Escherichia
Correspondence: Baskaralingam Vaseeharan, Department of Animal Health and Management, Alagappa University, Alagappa Nagar, Karaikudi630 003, Tamil Nadu, India.

Tel. +91.4565.225205 - Fax: +91.4565.225202.

E-mail: bvaseeharan@yahoo.co.in

vaseeharanb@gmail.com

Key words: silver nanoparticle, Vibrio alginolyticus, aquaculture, Artemia franciscana, Calotropis gigantea.

Acknowledgments: this work was supported by Indo-Taiwan programme of cooperation from Department of Science and Technology, New Delhi, India, (Project code ITRD003) and National Science Council (NSC 98-2923-B-019002), Taiwan. The authors thank Dr Junda Lin (Florida Institute of Technology, Melbourne, FL, USA) and Dr GP Brennan, Queens University Belfast, UK for their constructive comments on the manuscript.

Received for publication: 16 September 2011. Revision received: 4 January 2012. Accepted for publication: 12 January 2012.

This work is licensed under a Creative Commons Attribution NonCommercial 3.0 License (CC BYNC 3.0).

CC Copyright V. Baskaralingam et al., 2012 Licensee PAGEPress, Italy

Nanotechnology Development 2012; 2:e3 doi:10.4081/nd.2012.e3

coli, Pseudomonas aeruginosa,${ }^{14-16}$ viruses, ${ }^{17}$ pathogenic fungi, ${ }^{18}$ and eukaryotic microorganisms. However, there are still no available reports in scientific literature on antibacterial activity of AgNps against pathogenic bacteria causing disease in commercially important aquatic organisms. Therefore, the present study was undertaken to assess the inhibitory activity of AgNps synthesized by Calotropis gigantea leaf extract against pathogenic $V$. alginolyticus, and also to evaluate the in vitro inhibitory concentration of AgNps against $V$. alginolyticus blooms in Artemia hatching practices in aquaculture.

\section{Materials and Methods}

\section{Synthesis of AgNps from \\ $C$. gigantea leaf extracts}

Calotropis gigantea mediated synthesis of AgNps was carried out based on the green synthesis procedure with slight modifications..$^{19,20}$ $C$. gigantea leaves ( $6.5 \mathrm{~g})$ were washed thoroughly with sterile distilled water for $10 \mathrm{~min}$, air dried, finely cut and boiled for 15 min with $350 \mathrm{~mL}$ of sterile, distilled water. After boiling, the broth was cooled at room temperature and 
filtered through Whatman filter paper to obtain a clear, leaf broth. Silver nitrate $\left(\mathrm{AgNO}_{3}\right)$ (purchased from Sigma Aldrich company, product n. 204390; St Louis, MO, USA) was used for the synthesis of AgNps. In a typical synthesis, 75 $\mathrm{mL}$ of $0.01 \mathrm{M} \mathrm{AgNO}_{3}$ was added to $10 \mathrm{~mL}$ of leaf extract with continuous stirring, at $40^{\circ} \mathrm{C}$. Within $30 \mathrm{~min}$, a yellow colouration appeared, indicating the onset of AgNps formation. The synthesis of AgNps was monitored by UV-visible spectroscopy operating at the wavelength of 280-700 nm (ELICO SL 159, India) at time intervals of 1, 5, 10, 15, 20, 25 and 30 days. The synthesized AgNps were collected from Day 10 onwards and centrifuged at $5000 \mathrm{~g}$ at room temperature for $10 \mathrm{~min}$. The pellets were dried at $45^{\circ} \mathrm{C}$ for $24 \mathrm{~h}$ and the powder was dispensed in sterile, distilled water to obtain the required experimental concentration for the experiments. The size and the morphology of the AgNps were examined by Atomic Force Microscope (Veeco di CP-II, USA).

\section{Collection and identification of $V$. alginolyticus}

The experimental $V$. alginolyticus was isolated from the wild Artemia franciscana cysts (Veppalodai solar salt works, Tuticorin, India). ${ }^{21}$ Briefly, the total cyst microflora was counted using serial dilution method followed by a quadrant streaking method. Further pure cultures grown in TCBS agar (Himedia, Bombay, India) supplemented with $1.5 \% \mathrm{NaCl}$, were chosen and identified using standard biochemical methods. ${ }^{22}$ The $V$. alginolyticus (isolate code DHMVA07) strain was selected and confirmed by PCR and $16 \mathrm{~S}$ rDNA typing methods..$^{23}$ The pathogenicity of the strain was evaluated using experimental infection in $A$. franciscana nauplii $\left(\mathrm{LD}_{50}\right.$ value of $10^{5} \mathrm{CFU} \mathrm{mL} \mathrm{L}^{-1}$ in experimental infection of Artemia nauplii). The colony counts reported in the present study were estimated through serial dilution, plating and counting methods.

\section{Inhibitory activity against \\ V. alginolyticus}

Green synthesized AgNps were tested for antibacterial activity against pathogenic $V$. alginolyticus using the well-diffusion method. V. alginolyticus $\left(10^{4} \mathrm{CFU}\right)$ was inoculated on Muller-Hinton agar plates. 100 $\mu \mathrm{L}$ samples of synthesized AgNps (experimental), crude $C$. gigantea leaf broth and $\mathrm{AgNO}_{3}(0.75 \mathrm{mM}$ final concentration) solution were added to individual wells in separate plates. After incubation at $37^{\circ} \mathrm{C}$ for $24 \mathrm{~h}$, the zone of inhibition was measured. The minimum inhibitory concentration of the synthesized AgNps was determined using $10^{4}$ colony forming units (CFU) of $\mathrm{V}$. alginolyticus on Luria-Bertani (LB) agar plates supplemented with AgNps at concentrations of $5,10,15$, and $20 \mu \mathrm{g} \mathrm{mL}^{-1}$ (in triplicate). The plates were incubated for $24 \mathrm{~h}$ at $37^{\circ} \mathrm{C}$ and the numbers of colonies were counted. If the number of CFU on an agar plate was greater than 300 colonies, then the result was interpreted as being too numerous to count (TNTC). ${ }^{24}$

\section{Artemia nauplii hatching test}

The hatchability of $A$. franciscana (San Francisco Bay, USA) was evaluated following the procedure of Lavens and Sorgeloos. ${ }^{25}$ Prehydrated (160 mg) cysts were hatched in cylindroconical tubes containing $80 \mathrm{~mL}$ of pre-aerated filter sterilized sea water under constant illumination and aeration at $28^{\circ} \mathrm{C}$. Three experimental tubes in triplicate (control, $V$. algynolyticus, and AgNps $+V$. alginolyticus), were left for $24 \mathrm{~h}$ to assess the hatching percentage. $V$. alginolyticus $\left(4 \times 10^{5} \mathrm{CFU}\right)$ were used in this experiment with the concentration of $5 \mu \mathrm{g} / \mathrm{mL}$ AgNps (based on the effective minimum inhibitory concentration (MIC) determined through the previous experiment) in seawater. The hatching percentage was calculated with the following formula:

$$
\% \mathrm{H}=\frac{\mathrm{N}}{\mathrm{N}+\mathrm{C}+\mathrm{U}} \times 100
$$

where $\mathrm{N}=$ Number of nauplii; $\mathrm{C}=$ Number of unhatched cysts; $U=$ Number of umbrella stage nauplii.

\section{Artemia nauplii challenge infections}

Three test groups were set up in triplicate: Control (C), V. alginolyticus inoculated (V) and V. alginolyticus $+5 \mu \mathrm{g} / \mathrm{ml}$ AgNps (VN). Each group contained 100 Artemia nauplii (Instar I stage) inoculated in pre-aerated seawater (10 $\mathrm{mL}$ ), and was challenged with $V$. alginolyticus $\left(5 \times 10^{4} \mathrm{CFU}\right)$. The active napulii were considered live and were counted under a light microscope.

Survival rate was determined at $2 \mathrm{~h}$ intervals over the period of $12 \mathrm{~h}$. The survival percentage was calculated using the formula: survival rate $(\%)=[$ number of live nauplii at the $2 \mathrm{~h}$ intervals/number of nauplii at the time of inoculation $] \times 100$.

\section{Statistical analysis}

Experimental groups, percentage of hatched cysts and survival rates were analyzed by a one-way ANOVA followed by Tukeys Honest Significant Difference test $(P<0.05){ }^{26}$

\section{Results}

\section{Synthesis of AgNps from \\ C. gigantea leaf extracts}

The synthesis of AgNps was detectable following a color change in the reaction solution (C. gigantea leaf extract $+0.75 \mathrm{mM}$ silver ions) from Day 2 of incubation (UV-Vis spectra), and a distinct peak was observed at $410 \mathrm{~nm}$. The UV-Vis spectra show a slow shift in peak values and wavelength for the AgNps through the first ten days of the synthesis (Figure 1A). The peak values continued to increase during the incubation period (Figure 1B). After ten days, the change in the peak value and peak wavelength was reduced, and saturation was observed from Day 15. The depth profile using atomic force microscopy (AFM) shows the spherical arrangement of the synthesized AgNps particles, with a diameter range of $6.3-12.67 \mathrm{~nm}$ (Figure 2).

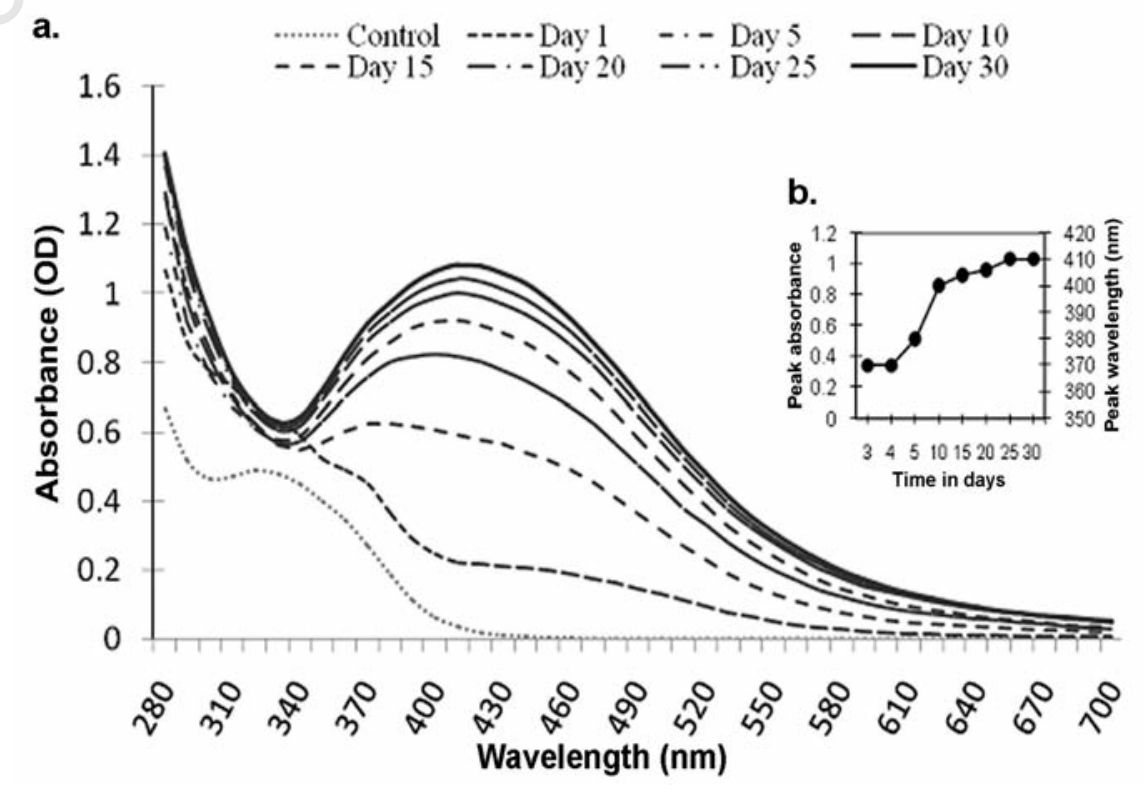

Figure 1. a. UV-visible reflective spectra of AgNps synthesis at different time intervals. b. Change in absorption peak and wavelength of the peak absorbance in time (Days). 


\section{In vitro inhibitory activity of}

\section{AgNps against $V$. alginolyticus}

AgNps synthesized with $C$. gigantea leaf extract showed a strong inhibitory activity against $V$. alginolyticus (well diffusion method). The inhibition zone for AgNps was $16 \mathrm{~mm}( \pm 0.25)$ in diameter, while that for the silver nitrate solution without synthesized AgNps was $2 \mathrm{~mm}$ in diameter. No zone of inhibition was observed for $C$. gigantea leaf extracts. Figure 3 shows the colony counts of $V$. alginolyticus ( $\left.10^{4} \mathrm{CFU}\right)$ grown on LB agar plates, supplemented with varying concentrations of AgNps $(5,10,15$, and $20 \mu \mathrm{g} / \mathrm{mL})$. More than 300 colonies were observed on the LB agar plates containing $5 \mu \mathrm{g} / \mathrm{mL}$ concentration of green synthesized AgNps (Figure 3). Higher concentrations of AgNps (10 and $15 \mu \mathrm{g} / \mathrm{mL}$ ) restricted the number of colonies on the LB agar plates to 116 and 17, respectively. At a concentration of $20 \mu \mathrm{g} / \mathrm{mL}$, AgNps totally inhibited the growth of $V$. alginolyticus.

\section{In vivo antibacterial activity of AgNps in an Artemia hatching setup}

The efficacy of AgNps in vivo against $V$. alginolyticus was tested in Artemia nauplii at hatching. The hatch rate for $A$. franciscana cysts treated with $5 \mu \mathrm{g} / \mathrm{mL}$ AgNps was significantly higher $(84 \%)$ than that of untreated cysts (64\%) infected with $V$. alginolyticus (Figure 4).

\section{A. franciscana nauplii survival rate}

A. franciscana nauplii treated with AgNps (5 $\mu \mathrm{g} / \mathrm{mL}$ ) (VN) showed significantly higher survival rate when compared to $V$. alginolyticus infected Artemia nauplii (V). There was no survival recorded for Control A. franciscana, following a $12 \mathrm{~h}$ exposure to $\mathrm{V}$. alginolyticus. Experimental infection studies also showed that $V$. alginolyticus infected Artemia nauplii, treated with AgNps (10 $\mu \mathrm{g} / \mathrm{mL}$ seawater), showed greater survival $(>40 \%)$ than that of non-AgNps treated Artemia nauplii (Figure 5).

\section{Discussion}

The application of metallic nanoparticles to control microbial mediated diseases remains largely unexplored. Several methods have been employed to synthesize AgNps, including green chemistry. Although a number of physical and chemical methods for the synthesis of AgNps are available, there is a need to develop an eco-friendly method for the synthesis process. ${ }^{27}$ The green synthesis of AgNps has been reported in bacteria and angiosperms. ${ }^{28-29}$ In the present study, aqueous extracts of $C$. gigantea were used to synthesize AgNps and tested against $V$. alginolyticus. Plant extracts are widely applied to synthesize AgNps by reducing $\mathrm{Ag}^{+}$ions into $\mathrm{Ag}^{0}$ ions, which increases the optical density of the solution. ${ }^{30}$ This is due to the excitation of SPR (surface plasmon resonance) and the reduction of silver nitrate during the incubation period. ${ }^{31}$ The shift in the spectral peak value observed in the present study is due to a variation in the size and shape of the synthesized AgNps (Figure 1). ${ }^{32}$ An increase in absorption spectra (350-600 $\mathrm{nm}$ ) did not affect the spectral region of $\sim 410$ $\mathrm{nm}$, indicating that the particles present in the broth were not aggregating. ${ }^{12}$ AFM revealed that the size of the AgNps synthesized during this study was $6-12 \mathrm{~nm}$. Several studies have reported that efficient antimicrobial properties of AgNps were dictated by the small size and surface planar accessibility of the AgNps. ${ }^{18,33,13}$
Lower concentrations of AgNps (5, 10, 15 and $20 \mu \mathrm{g} \mathrm{mL}^{-1}$ ) on LB agar plates effectively reduced the number of $V$. alginolyticus colonies. A gradual decrease in CFUs on LB agar plates was observed at $5 \mu \mathrm{g} / \mathrm{mL}$ AgNps, while a total inhibition of $V$. alginolyticus was achieved at $20 \mu \mathrm{g} / \mathrm{mL}$ concentration of AgNps. According to Nanda and Saravanan, ${ }^{16} 2 \mu \mathrm{g}$ of biosynthesized AgNps failed to show a zone of inhibition against $V$. cholera. When different concentrations of AgNps were incorporated on the LB agar plates, the bacterial growth was completely inhibited at or above a desired concentration. The concentration of the nanoparticles and the decrease in bacterial CFU influences the complete inhibition. The mechanism of the bactericidal action of AgNps is only partially understood. Nanosilver particles can enter into the bacterial cells, ${ }^{26}$ possibly by dis-

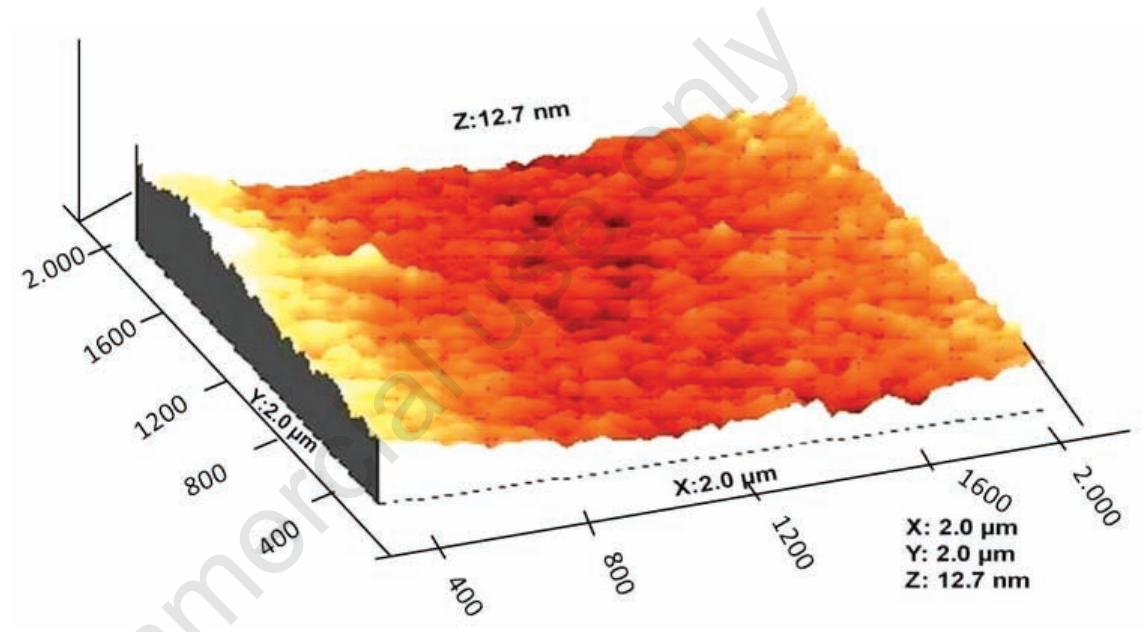

Figure 2. Atomic force microscopy depth resolved image of AgNps synthesized by $C$. gigantea leaf extract.

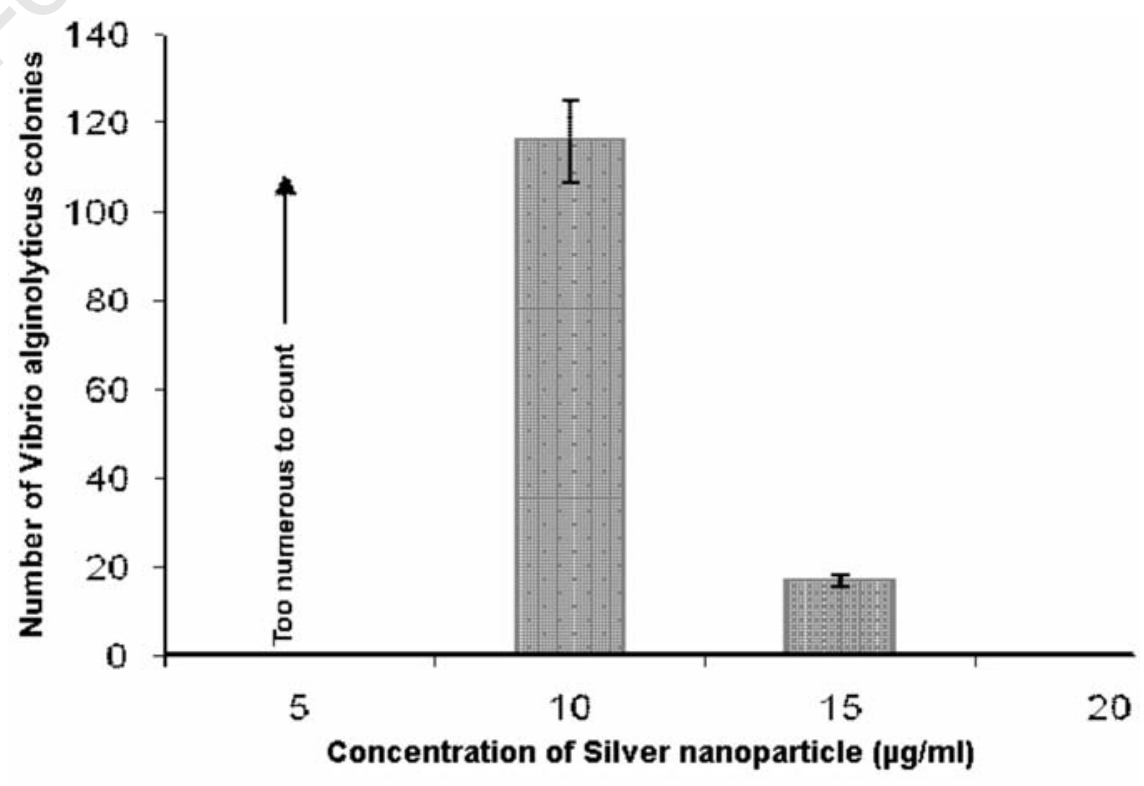

Figure 3. Inhibitory activity of AgNps synthesized by $C$. gigantea leaf extract at different concentrations $(\mu \mathrm{g} / \mathrm{mL})$ against V. alginolyticus. 
turbing the cell permeability and respiratory functions. ${ }^{25} \mathrm{Ag}^{+}$ions suppress the bacteria by affecting the sulphur group of the biomolecules. $^{32}$ It has been suggested that the nanoparticles cause cell wall protein and other protein denaturation and prevent the replication process taking place. ${ }^{14,17}$ We observed that $5 \mu \mathrm{g}$ (per $100 \mathrm{~mL}$ of hatching media) of AgNps present in hatching medium improved the hatching percentage. The nauplii challenge tests provide convincing evidence that AgNps

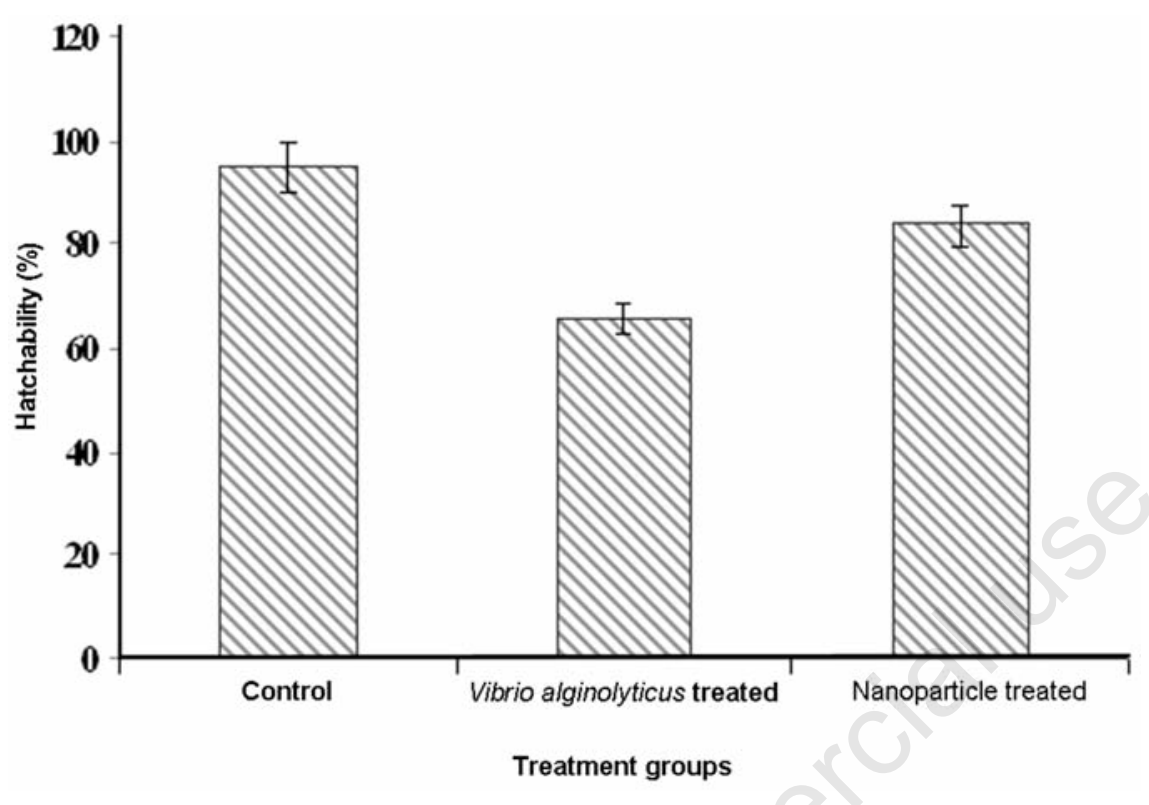

Figure 4. Hatch rate for of Artemia franciscana cysts after $V$. alginolyticus challenge ( $\left.4 \times 10^{5} \mathrm{CFU}\right)$



Figure 5. Effect of AgNps on the survival rate (\%) of Artemia nauplii during V. alginolyticus challenge $\left(4 \times 10^{5}\right)$. can control and eradicate V. alginolyticus from the hatching medium. Artemia cysts and nauplii are suitable for analyzing the activity of antibacterial substances in seawater systems..$^{15}$ Application of antibiotics to control the pathogens may involve the development of a risk factor of resistance as well as transfer of virulent genes. Therefore, immediate attention should be given to trying alternative strategies to control microbes. Alternatively, the safe use of plant-based AgNps in higher organisms requires relatively a low concentration for effective control activities. Silver has a long history as a germicide and has little or no toxic impact at low concentrations. ${ }^{22}$ Nano material research and risk assessments will ultimately need to address multiple potential health related aspects of aquatic animal diseases. Even though there is no report yet available on the application of AgNps in controlling Vibrio species, it appears that aquatic animals can be employed to evaluate nanoparticle toxicity. ${ }^{34}$ In conclusion, the green synthesis of metallic nanoparticles on overcoming multidrug resistant bacterial pathogens is still an unexplored area of research, and the present study has made an attempt to show the capability of AgNps to control Vibrio as an experimental model. The study successfully demonstrated that AgNps synthesized from $C$. gigantea leaf extract can control $V$. alginolyticus in an Artemia culture system. Further studies are needed to assess the long-term toxic effects of AgNPs in the system, and to extend this knowledge to other experimental models.

\section{References}

1. Brigger I, Dubernet C, Couvreur P. Nanoparticles in cancer therapy and diagnosis. Adv Drug Deliv Rev 2002;54:631-51.

2. Bondad-Reantaso M, Subasinghe RP, Arthur JR, et al. Disease and health management in Asian aquaculture. Vet Parasitol 2005;132:249-27.

3. Pal S, Tak YK, Song JM. Does the antibacterial activity of silver nanoparticles depend on the shape of the nanoparticle? a study of the gram-negative bacterium. Appl Envir Microbiol 2007;73:1712-20.

4. Grisez L, Chair M, Sogerloos P, Ollevier F. Mode of infection and spread of Vibrio anguillarum in turbot Scophthalmus maximus larvae after oral challenge through live feed. Dis Aquat 1996;26:181-7.

5. Vineet-Kumar, Kumar SY. Plant-mediated synthesis of silver and gold nanoparticles and their applications. J Chem Technol Biotechnol 2009;84:151-7.

6. Austin B, Zhang XH. Vibrio harveyi: a significant pathogen of marine vertebrates and invertebrates. Lett Appl Microbiol 2006;43:119-24.

7. Austin B, Austin DA. Bacterial fish pathogens, disease of farmed and wild fish. Godalming: Springer Praxis; 2007.

8. Lavens P, Sorgeloos P. Manual on the production and use of live food for aquaculture. FA0 Fisheries Technical Paper 361, 1996, p 295.

9. Villamil L, Figueras A, Planas M, Novoa, B. Control of Vibrio alginolyticus in Artemia culture by treatment with bacterial probi- 
otics. Aquaculture 2003;219:43-56.

10. Austin B. Vibrios as causal agents of zoonoses. Vet Microbiol 2009;140:310-7.

11. Ingle $A$, Gade $A$, Pierrat $S$, et al. Mycosynthesis of silver nanoparticles using the fungus Fusarium acuminatum and its activity against some human pathogenic bacteria. Curr Nanosci 2008;4:141-4.

12. Birla SS, Tiwari VV, Gade AK, et al. Fabrication of silver nanoparticles by Phoma glomerata and its combined effect against Escherichia coli, Pseudomonas aeruginosa and Staphylococcus aureus. Lett Appl Microbiol 2009;48:173-9.

13. Fayaz A, Balaji K, Girilal M, et al. Biogenic synthesis of silver nanoparticles and their synergistic effect with antibiotics: a study against gram-positive and gram-negative bacteria. Nanomedicine 2010;6:103-9.

14. Gade AK, Bonde PP, Ingle AP, et al. Exploitation of Aspergillus niger for fabrication of silver nanoparticles. Biobased Mater Bioenergy 2008;2:243-7.

15. Morones JR, Elechiguerra JL, Camacho A, et al. The bactericidal effect of silver nanoparticles. Nanotechnology 2005;16: 2346-53.

16. Nanda A, Saravanan M. Biosynthesis of silver nanoparticles from Staphylococcus aureus and its antimicrobial activity against MRSA and MRSE. Nanomed. Nanotechnol. Biol Med 2009;5:452-6.

17. Vaseeharan B, Raffiq Hussian M, Chen JC. RpoN gene, RAPD profile, antimicrobial resistance and plasmids of Vibrio anguillarum isolates from vibriosis infected
Penaeus monodon. Lett Appl Microbiol 2008;47:380-5.

18. Pommerville JC. Alcamo's Laboratory Fundamentals of Microbiology. $7^{\text {th }}$ ed. 2007, p 282.

19. Shiv Shankar S, Ahmad A, Sastry M. Geranium leaf assisted biosynthesis of silver nanoparticles. Biotechnol Progr 2008; 19:1627-31.

20. Wang YB, Lia JR, Lin J. Probiotics in aquaculture: Challenges and outlook. Aqua-culture 2008;281:1-4.

21. Alsina M, Blanch A. Improvement and update of a set of keys for biochemical identification of Vibrio species. J Appl Bacteriol 1994;77:719-21.

22. Holt JG, Krieg NR, Sneath PHA, et al. Facultative anaerobic Gram-negative rods. Subgroup 2: family Vibrionaceae. In: Bergey's Manual of Determinative Microbiology. 9th ed. Williams and Wilkins, Baltimore, USA. 1994;190-253.

23. Liu CH, Cheng W, Hsu JP, Chen JC. Vibrio alginolyticus infection in the white shrimp Litopenaeus vannamei confirmed by polymerase chain reaction and $16 \mathrm{~S}$ rDNA sequencing. Dis Aquat Org 2004;61:169-74.

24. Sathishkumar M, Sneha K, Won SW, et al. Cinnamon zeylanicum bark extract and powder mediated green synthesis of nanocrystalline silver particles and its bactericidal activity. Colloids Surf 2009;73:332-8.

25. Lavens P, Sorgeloos P. Manual on the Production and Use of Live Food for Aquaculture. FAO Fisheries Technical Paper 361. 1996, p 295.
26. Sondi I, Sondi B. Silver nanoparticles as antimicrobial agents a case study on E-coli as a model for Gram-negative bacteria. Colloid Interface 2004;275:177-82.

27. Elechiguerra JL, Burt JL, Morones JR, et al. Interaction of silver nanoparticles with HIV1. Nanobiotechnol 2005;3:6.

28. Mandal D, Bolander ME, Mukhopadhyay D, et al. The use of microorganisms for the formation of metal nanoparticles and their application. Appl Microbiol Biotechnol 2006;69:485-92.

29. Snell TW, Hicks DG. Assessing toxicity of nanoparticles using Brachionus manjavacas (Rotifera). Environ Toxicol 2010;26: 146-52

30. Song YJ, Kim BS. Rapid biological synthesis of silver nanoparticles using plant leaf extracts. Bioprocess Biosyst Eng 2009;32: 79-84.

31. Mulvaney P. Surface plasmon spectroscopy of nanosized metal particles. Langmuir 1996;12:788-800.

32. He R, Qian X, Yin J, Zhu Z. Preparation of polychrome silver nanoparticles in different solvents. J. Mater. Chem 2002;12:3783-6.

33. Song JY, Kim BS. Rapid biological synthesis of silver nanoparticles using plant leaf extracts. Bioprocess Biosyst Eng 2009;32: 79-84.

34. Son WK, Youk JH, Lee TS, Park WH. Preparation of antimicrobial ultrafine cellulose acetate fibers with silver nanoparticles. Macromol Rapid Commun 2004;25: 1632-7. 